\title{
MENINGKATKAN PROMOSI DAN EVALUASI PENERAPAN \\ BUDAYA KESELAMATAN PASIEN UNTUK MENCIPTAKAN \\ KEPUASAN DALAM PELAYANAN DI RUMAH SAKIT
}

\author{
Julia Rahma/191101040 \\ emasurya123emasurya123@gmail.com
}

\begin{abstract}
ABSTRAK
Rumah sakit merupakan salah satu bentuk sarana kesehatan yang berfungsi untuk melakukan upaya kesehatan dasar, atau kesehatan rujukan dan upaya kesehatan penunjang. Keberhasilan rumah sakit dalam menjalankan fungsinya ditandai dengan adanya mutu pelayanan prima rumah sakit. Perkembangan ilmu pengetahuan dan tekhnologi yang sedemikian pesat menyebabkan pelayanan kesehatan di rumah sakit menjadi sangat kompleks sehingga jika tidak dilakukan dengan benar dan hati-hati akan berpotensi untuk terjadinya Insiden Keselamatan Pasien (IKP) yang terdiri dari Kejadian Tidak Diharapkan (KTD), Kejadian Nyaris Cedera (KNC), Kejadian Tidak Cedera (KTC) dan Kondisi Potensial Cedera (KPC) (Depkes,2006). Permasalahan keselamatan pasien di rumah sakit merupakan masalah yang memerlukan penanganan segera karena dapat mengakibatkan cedera langsung pada pasien.
\end{abstract}

Kata Kunci : promosi dan evaluasi penerapan, kerselamatan pasien, cedera.

\section{LATAR BELAKANG}

Rumah sakit merupakan salah satu bentuk sarana kesehatan yang berfungsi untuk melakukan upaya kesehatan dasar, atau kesehatan rujukan dan upaya kesehatan penunjang. Keberhasilan rumah sakit dalam menjalankan fungsinya ditandai dengan adanya mutu pelayanan prima rumah sakit. Faktor yang paling dominan yang mempengaruhi mutu adalah sumber daya manusia. Budaya keselamatan pasien merupakan suatu hal yang penting karena membangun budaya keselamatan pasien merupakan suatu cara untuk membangun program keselamatan pasien secara keseluruhan. Temuan awal diketahui angka infeksi nosokomial telah mencapai rerata 3.74\%, sedangkan standar acuan Depkes RI 2008 adalah kurang dari $1.5 \%$. 
Berbagai layanan dapat diakses oleh pasien yang membutuhkan bantuan. Pasien yang memerlukan bantuan menyeluruh dan intensif selama 24 jam dapat mengakses layanan rawat inap. Perawatan rawat inap memiliki peran penting dalam pelayanan perawatan untuk observasi, diagnosis, pengobatan atau upaya perawatan kesehatan lainnya. Keselamatan pasien di rumah sakit melibatkan partisipasi dari semua petugas kesehatan, terutama perawat.

Perawat adalah pejabat eksekutif kesehatan dengan waktu kerja tertinggi yang memberikan 24 jam pelayanan terus menerus serta harus berkolaborasi dengan tim kesehatan lain dan oleh karena itu lah hal tersebut dapat menyebabkan atau berisiko terjadinya Insiden Keselamatan Pasien. Selain itu, perawat memiliki peran yang paling dominan dalam mencegah terjadinya kesalahan dalam pengobatan, termasuk pelaporan insiden, mendidik diri sendiri dan orang lain. Sejalan dengan definisi keperawatan ANA 2003 yang menyatakan bahwa keperawatan adalah perlindungan, promosi, dan optimalisasi kesehatan dan kemampuan, pencegahan penyakit dan cedera, pengentasan penderitaan melalui diagnosis dan pengobatan respon manusia, dan advokasi dalam perawatan individu, keluarga, masyarakat, dan populasi.

Tahap penilaian atau evaluasi adalah perbandingan yang sistematik dan terencana tentang kesehatan klien dengan tujuan yang telah ditetapkan, dilakukan dengan cara bersinambungan dengan melibatkan klien dan tenaga kesehatan lainnya dan merupakan tahap akhir dari rangkaian proses keperawatan yang berguna apakah tujuan dari tindakan keperawatan yang telah dilakukan tercapai atau perlu pendekatan lain. Sesuai dengan rencana tindakan yang telah diberikan, dilakukan penilaian untuk melihat keberhasilannya. Bila tidak atau belum berhasil, perlu disusun rencana baru yang sesuai. Semua tindakan keperawatan mungkin tidak dapat dilaksanakan dalam satu kali kunjungan ke keluarga. Untuk itu dapat dilaksanakan secara bertahap sesuai dengan waktu dan kesediaan keluarga.

\section{METODE}

Metode yang digunakan dalam kajian ini adalah metode Litterature review dengan menganalisis, eksplorasi dan kajian bebas. Dimana hasil analisis ini bisa didapat sumber yaitu dengan membandingkan antar satu jurnal dengan jurnal yang lain. Kajian ini juga dapat 
dibuat dengan mencari berbagai sumber referensi lainnya baik itu ejournal maupun skripsi yang berkenaan dengan evaluasi penerapan budaya keselamatan pasien.

\section{HASIL}

Rumah Sakit adalah institusi pelayanan kesehatan yang menyelenggarakan pelayanan kesehatan perorangan secara paripurna dan menyediakan pelayanan rawat inap, rawat jalan, serta gawat darurat. Tenaga kesehatan yang bekerja di Rumah Sakit harus bekerja sesuai dengan standar profesi, standar pelayanan rumah sakit, standar prosedur operasional yang berlaku, etika profesi, menghormati hak pasien dan mengutamakan keselamatan pasien (Undang-Undang No 44, 2009).

Pelayanan keperawatan yang diberikan kepada pasien, dapat menimbulkan risiko keselamatan pasien yang begitu besar. Kejadian insiden keselamatan pasien yang terjadi di rumah sakit banyak yang tidak dilaporkan dikarenakan laporan yang diadakan tersebut akan dikaitkan dengan area kerja pada insiden yang terjadi. Hasilnya, para pengambil kebijakan di rumah sakit tidak mengetahui peringatan akan potensial terjadinya bahaya yang dapat menyebabkan error (Tamuz et al, 2002).

Berdasarkan data insiden Keselamatan Pasien yang diterbitkan KKPRS (Komite Keselamatan Pasien Rumah Sakit) terdapat 114 laporan insiden keselamatan pasien pada tahun 2009, 103 laporan pada tahun 2010, dan 34 laporan di tahun 2011 pada tri wulan I (KKPRS, 2012). Laporan insiden keselamatan pasien dari KKP-RS (2010), mengenai Kejadian Tidak Diharapkan (KTD) pada tahun 2007 di Indonesia terjadi peningkatan kasus KTD dari 46,2\% menjadi 63\%. Dampaknya adalah memperpanjang masa rawat, meningkatkan cidera, kematian, perilaku saling menyalahkan, konflik antara petugas dan pasien, tuntutan dan proses hukum, blow up media massa, dapat menurunkan citra dari sebuah rumah sakit, serta dapat mengindikasikan bahwa mutu pelayanan di rumah sakit masih kurang baik (AHRQ, 2013).

Evaluasi adalah aktivitas yang direncanakan, berkelanjutan, dan terarah ketika klien dan professional kesehatan menentukan kemajuan klien menuju pencapaian tujuan atau hasil keefektifan rencana asuhan keperawatan dengan tindakan intelektual dalam melengkapi proses keperawatan yang menandakan keberhasilan untuk diagnosa keperawatan, rencana intervensi dan implementasinya dalam penerapan budaya keselamatan pasien. 


\section{PEMBAHASAN}

Salah satu prinsip pelayanan kesehatan adalah menyelamatkan pasien dengan prosedur dan tindakan yang aman dan tidak membahayakan pasien maupun petugas pemberi pelayanan kesehatan. Setiap fasilitas layanan kesehatan harus selalu menjaga keamanan proses pelayanan kesehatannya guna menghindari terjadinya kesalahan medis (medical error) yang bisa berpengaruh terhadap kualitas pelayanan kesehatan.

Keselamatan pasien merupakan suatu upaya menjamin segala tindakan dan aktivitas yang berhubungan dengan pasien yang dilakukan oleh petugas kesehatan agar berlangsung dengan aman dan tidak menimbulkan efek atau dampak yang membahayakan bagi pasien melalui serangkaian aktivitas yang telah diatur dalam perundang-undangan.

Keselamatan pasien menjadi poin penting dalam setiap tindakan medis baik tindakan medis ringan maupun tindakan medis berat. Berdasarkan penelitian Maghfiroh \& Rochmah (2017), keselamatan pasien memberikan pengaruh besar terhadap citra, tanggung jawab sosial, moral serta kinerja petugas kesehatan sehingga keselamatan pasien memiliki keterkaitan dengan isu mutu dan citra sebuah pelayanan kesehatan termasuk puskesmas.

Menurut Institute of Medicine (IOM) keselamatan pasien memiliki pengertian bebas dari kejadian cedera. Selain pengertian tersebut patient safety dapat diartikan sebagai the prevention of harm patient penekanan ditempatkan pada pemberi perawatan yang mencegah kesalahan, belajar dari kesalahan yang terjadi dan dibangun di atas sebuah budaya keselamatan pasien yang melibatkan perawat kesehatan profesional, organisasi, dan pasien. Hal tersebut diperluas oleh Agency of Healthcare Research and Quality(AHRQ) keselamatan pasien diartikan sebagai bebas dari cedera yang disengaja atau cedera yang dicegah yang dihasilkan oleh petugas medis (AHRQ, 2008) dalam (Beginta, 2012). Dalam Depkes (2006), tujuan dari Sistem Keselamatan Pasien Rumah Sakit adalah:

1. Terciptanya budaya keselamatan pasien di rumah sakit

2. Meningkatnya akutanbilitas rumah sakit terhadap pasien dan masyarakat

3. Menurunnya kejadian tidak diharapkan (KTD) di rumah sakit. 
4. Terlaksananya program-program pencegahan sehingga tidak terjadi pengulangan kejadian tidakdiharapkan.

Keselamatan Pasien adalah suatu sistem yang membuat asuhan pasien lebih aman, meliputi assesment risiko, identifikasi dan pengelolaan risiko pasien, pelaporan dan analisis insiden, kemampuan belajar dari insiden dan tindak lanjutnya, serta implementasi solusi untuk meminimalkan timbulnya risiko dan mencegah terjadinya cedera yang disebabkan oleh kesalahan akibat melaksanakan suatu tindakan atau tidak mengambil tindakan yang seharusnya diambil (Permenkes, 2011).

Keselamatan merupakan prinsip dasar dalam pelayanan pasien dan komponen kritis dari manajemen mutu Keselamatan pasien adalah sebuah transformasi budaya, dimana budaya yang diharapkan adalah budaya keselamatan, budaya tidak menyalahkan, budaya lapor dan budaya belajar Keselamatan Pasien (Patient Safety) merupakan isu global dan komponen penting dari mutu layanan kesehatan, prinsip dasardari pelayanan pasien dan komponen kritis dari manajemen mutu. Di Indonesia, program keselamatan pasien dicanangkan pada tahun 2005, dan terus berkembang menjadi isu utama dalam pelayanan medis di Indonesia

Menurut The Health Foudation, 2011, budaya keselamatan berkaitan dengan sejauh mana organisasi memprioritaskan dan mendukung peningkatan keselamatan dengan aman. Organisasi dengan budaya keselamatan positif memiliki komunikasi atas dasar saling percaya, persepsi bersama tentang pentingnya keselamatan, keyakinan pada efektivitas langkah-langkah pencegahan, dan dukungan bagi tenaga kerja.

Dalam hal menganalisis budaya keselamatan pasien dapat dilihat dari pengukuran indikator pola komunikasi, sistem pelaporan insiden (organisasi pembelajar), kerjasama tim, pendidikan dan pelatihan, iklim kerja, komitmen pimpinan, dan no blaming culture. Banyak kejadian insiden yang terjadi kemudian tidak dilaporkan yang dikarenakan laporan yang diadakan tersebut akan dikaitkan dengan area kerja pada insiden yang terjadi. Hasilnya, para pengambil kebijakan di rumah sakit tidak mengetahui peringatan akan potensial bahaya yang dapat menyebabkan error. Pencegahan kesalahan yang akan terjadi tersebut juga dapat menurunkan biaya yang dikeluarkan pasien akibat perpanjangan masa rawat yang mungkin terjadi. Keselamatan pasien (patient safety) meliputi: angka kejadian infeksi nosokomial, 
angka kejadian pasien jatuh, kesalahan dalam pemberian obat, dan tingkat kepuasan pasien terhadap pelayanan kesehatan.

Evaluasi merupakan langkah proses keperawatan yang memungkinkan perawat untuk menentukan apakah intervensi keperawatan telah berhasil meningkatkan kondisi klien (Potter \& Perry 2007) Evaluasi dimulai dengan pengkajian dasar dan dilanjutkan selama setiap kontak yang ditentukan oleh status klien atau kondisi yang dievaluasi. Evaluasi yang efektif ditandai pada langkah yang sebelumnya dilakukan. Kegiatan evaluasi hampir sama dengan kegiatan pengkajian.

Komponen evaluasi dapat dibagi menjadi 5 komponen yaitu:

1. Menetukan Kriteria,Standar Praktik, Pertanyaan Evaluatif Kriteria digunakan sebagai pedoman observasi pengumpulan data dan sebagai penentuan kebenaran data yang terkumpul. Standar Praktik dapat digunakan untuk mengevaluasi praktik keperawatan yang secara luas. Pertanyaan Evaluatif untuk menentukan suatu kriteria dan standar, perlu digunakan pertanyaan evaluatif sebagai dasar mengevaluasi kualitas asuhan keperawatan dan respons klien terhadap intervensi.

2. Mengumpulkan Data mengenai status kesehatan klien yang baru terjadi. Pada tahap ini kita perlu mempertimbangkan beberapa pertanyaan yaitu Siapa yang bertanggung jawab dalam pengumpulan data dan juga kapan data tersebut diperoleh, dan sarana apa saja yang akan digunakan untuk memperoleh data.

3. Menganalisis dan membandingkan data terhadap kriteria dan standar Seorang perawawat memerlukan suatu keterampilan dalam berpikir kritis, kemampuan menyelesaikan masalah, dan kemampuan mengambil keputusan dan pentingnya suatu data dengan cara membandingkan data evaluasi dengan kriteria dan standar yang sudah ada.

4. Merangkum hasil dan membuat kesimpulan Menyimpulkan efektivitas semua intervensi yang telah dilaksanakan. Kemudian menentukan kesimpulan pada setiap diagnosis yang telah dilakukan intervensi.

5. Melaksanakan intervensi sesuai yang sesuai berdasarkan kesimpulan Perawat melakukan intervensi berdasarkan hasil kesimpulan yang sudah diperbaiki dan perencanaan ulang,tujuan,kriteria hasil, dan rencana asuhan keperawatan 
Adapun jenis - jenis evaluasi yaitu:

1. Evaluasi formatif Pada evaluasi proses adalah aktivitas dari proses keperawatan dan hasil kualitas pelayanan asuhan keperawatan. Evaluasi proses harus ini dilaksanakan segera setelah perencanaan asuhan keperawatan di implementasikan untuk membantu menilai efektivitas intervensi tersebut. Evaluasi proses harus terus menerus dilaksanakan hungga tujuan yang telah ditentukan tercapai.

2. Evaluasi sumatif Rekapitulasi dan kesimpulan dari observasi dan analisa status kesehatan sesuai wakti pada tujuan. Ditulis pada catatan perkembangan. Fokus evaluasi hasil (sumatif) adalah perubahan perilaku atau status kesehatan klien pada akhir asuhan keperawatan.

Dalam melaksanakan asuhan keperawatan kepada pasien, perawat akan selalu membutuhkan bantuan dari perawat maupun tenaga kesehatan yang lainnya, korelasi antara unit kerja/kerjasama dengan penerapan patient safety adalah bermakna, kerjasama yang dilakukan didalam unit kerja masing masing.

Kerjasama yang baik tentu akan menghasilkan penerapan budaya keselamatan pasien yang baik. Penerapan budaya keselamatan pasien yang adekuat harus ditunjang oleh seluruh unit di rumah sakit tersebut. Unit-unit ini diharapkan dapat bekerja sama membentuk suatu sistem kerja sehingga proses pelayanan kesehatan dapat berjalan dengan optimal. Terwujudnya pelayanan kesehatan yang bermutu dan aman tergantung pada kokohnya sistem yang dibangun dari unit-unit yang ada di rumah sakit.

Untuk menjamin keselamatan pasien dalam kesinambungan pelayanan, di rumah sakit harus terdapat komunikasi dan transfer informasi antar profesi kesehatan sehingga dapat tercapainya proses koordinasi tanpa hambatan, aman, dan efektif. Hal ini didukung dengan hasil wawancara dengan informan kunci sebagai berikut: "Terdapat transfer informasi antar profresi kesehatan karena kalau pelayanan hanya dilakukan dokter saja maka pelayanan tidak akan berjalan dengan lancar".

\section{PENUTUP}

Salah satu prinsip pelayanan kesehatan adalah menyelamatkan pasien dengan prosedur dan tindakan yang aman dan tidak membahayakan pasien maupun petugas pemberi pelayanan 
kesehatan. Setiap fasilitas layanan kesehatan harus selalu menjaga keamanan proses pelayanan kesehatannya guna menghindari terjadinya kesalahan medis (medical error) yang bisa berpengaruh terhadap kualitas pelayanan kesehatan.

Evaluasi adalah proses pemberian makna atau ketetapan kualitas hasil pengukuran dengan cara membandingkan angka hasil pengukuran atau dapat pula kriteria tertentu. Kriteria sebagai pembanding dari proses pengukuran atau dapat pula ditetapkan sesudah pelaksanaan pengukuran. Kriteria ini dapat berupa proses / kemampuan rata-rata unjuk kerja kelompok dan berbagai patokan lain. (Hamzah B. Uno dan Satria Koni, 2012). Untuk menjamin keselamatan pasien dalam kesinambungan pelayanan, di rumah sakit harus terdapat komunikasi dan transfer informasi antar profesi kesehatan sehingga dapat tercapainya proses koordinasi tanpa hambatan, aman, dan efektif. Hal ini didukung dengan hasil wawancara dengan informan kunci sebagai berikut: "Terdapat transfer informasi antar profresi kesehatan karena kalau pelayanan hanya dilakukan dokter saja maka pelayanan tidak akan berjalan dengan lancar".

\section{DAFTAR PUSTAKA}

Adawiyah,R., Thamrin., \& Djafar,L. (2012). Evaluasi pelayanan yang diberikan oleh Perawat pada ruang kelas III Rumah Sakit Umum Daerah Dokter Soedarso. Jurnal Tesis PMISUNTAN-IAN. Vol 1

Anggraini, D., Hakim, L., \& Imam, C. W.(2014). Evaluasi Pelaksanaan Sistem Identifikasi Pasien di Instalasi Rawat Inap Rumah Sakit. Jurnal Kedokteran Brawijaya, $28(1)$

Astuti, Syahril A. Painringi, Abdul Rahman Kadir, (2018), PENGARUH ELEMEN PEOPLE PADA KNOWLEDGE MANAGEMENT TERHADAP BUDAYA KESELAMATAN PASIEN DI RSUDA.M PARIKESIT TENGGARONG (INFLUENCE ELEMENT PEOPLE OF KNOWLEDGE MANAGEMENT TO PATIENT SAFETY CULTURE AT A.M PARIKESIT TENGGARONG HOSPITAL), JKMM,Vol.2(1) 178-94 2.

Basok Buhari, (2019), BUDAYA KESELAMATAN PASIEN RUMAH SAKIT PEMERINTAH DAN RUMAH SAKIT SWASTA DI KOTA JAMBI, Jurnal 'Aisyiyah Medika Volume 3 (1) 
Busono, P. B. T. (2010). Evaluasi Penerapan Model Praktek Keperawatan Profesional di ruang Maranata I Rumah Sakit Mardi Rahayu Kudus (Doctoral dissertation, Universitas Diponegoro)

Herawati Tri Yennike, (2015), BUDAYA KESELAMATAN PASIENDI RUANG RAWAT INAP RUMAH SAKIT $\mathrm{X}$ KABUPATEN JEMBER (Patient Safety CultureInpatient In The Hospital X District Jember), Jurnal IKESMA, Volume $11(1)$

Heriyati, Muhammad Fauzar Al-Hijrah, Masniati, (2019), Budaya Keselamatan Pasien Rumah Sakit Umum Daerah Majene, Jurnal Kesehatan, Vol. 2 (3)

Iriviranty Afrisya, (2015), Analisis Budaya Organisasi dan Budaya Keselamatan Pasien Sebagai LangkahPengembanganKeselamatan Pasien di RSIABudi Kemuliaan Tahun 2014Analysis of Patient Safety Culture and Organizational Culture as a Step of Patient Safety Improvement in Budi Kemuliaan Hospital 2014, Jurnal Administrasi Rumah Sakit, Volume 1 (3)

Juniarti, N . H . Mudayana, A. A. (2018). PENERAPAN STANDAR KESELAMATAN PASIEN DI RUMAH SAKIT UMUM DAERAH PROVINSI NUSA TENGGARA BARAT. Jurnal Kesehatan Poltekkes Ternate, 11(2)

Nugroho Sri Hananto P, Untung Sujianto, (2017), SUPERVISI KEPALA RUANG MODEL PROCTOR UNTUK MENINGKATKAN PELAKSANAAN KESELAMATAN PASIEN, Jurnal Keperawatan Indonesia, Volume20 (1)

Simamora, R. H., \& Fathi, A. (2019). The Influence Of Training Handover Based SBAR Communication For Improving Patients Safety. Indian Journal Of Public Health Research \& Development, 10(9), 1280-1285. 